\title{
EXPLORING COMPUTER ETHICS ISSUES IN MALAYSIA
}

\author{
Maslin Masrom, University Technology Malaysia, maslin@ic.utm.my \\ Zuraini Ismail, University Technology Malaysia, zurainisma@ic.utm.my \\ Rashidah Nural Anuar, University Technology Malaysia, rashidah@ic.utm.my \\ Ramlah Hussein, International Islamic University Malaysia, ramlah@iiu.edu.my \\ Norshidah Mohamed, International Islamic University Malaysia, norshidah@iiu.edu.my
}

\begin{abstract}
In modern society nowadays, the development of information technology (IT) is indispensable to life. The use of IT has provided advantages for people, organizations, and society as a whole. Nevertheless, the widespread and rapid use of IT in society has exacerbated existing ethical issues or dilemmas, and also led to the emergence of new ethical issues such as unauthorized access, software piracy, internet pornography, privacy protection, information gaps, and many others. This paper presents a pilot study using a questionnaire administered to Malaysian students of higher education. Although there are many computer ethics issues, we confine our study of ethical issues to three main issues, namely accuracy, privacy and pirating of intellectual property. Several computer ethics scenarios that relate to the accuracy, privacy and intellectual property are also present in this paper.
\end{abstract}

Keywords: Computer Ethics, Accuracy, Privacy, Intellectual Property, IT Ethical Scenario

\section{INTRODUCTION}

The misuse of computer and information technology (IT) and unethical behavior towards IT have caused significant losses to society and business [1]. It continues to be one of the major problems in the current age. Computer Ethics is a branch of practical philosophy which deals with how computing professionals should make decisions regarding professional and social conduct.

The term "computer ethics" was first coined by Walter Maner [2, 3] in the mid-1970s, but only since the 1990s has it started being integrated into professional development programs in academic settings. The conceptual foundations of computer ethics are investigated by information ethics, a branch of philosophical ethics established by Luciano Floridi [4]. Computer ethics is an important topic in computer applications.

Information ethics is the field that investigates the ethical issues arising from the development and application of information technologies. It provides a critical framework for considering moral issues concerning informational privacy, moral agency (for example, whether artificial agents may be moral), new environmental issues (especially how agents should one behave in the info sphere), problems arising from the life-cycle (creation, collection, recording, distribution, processing, etc.) of information (especially ownership and copyright, digital divide). Information Ethics is related to the fields of computer ethics [5] and the philosophy of information.

Ethical issue or dilemma is a situation that will often involve an apparent conflict between moral imperatives, in which to obey one would result in transgressing another. It is regarding the life of information are becoming increasingly important in a society that is defined as "the information society".

Information transmission and literacy are essential concerns in establishing an ethical foundation that promotes fair, equitable, and responsible practices. Information ethics broadly examines issues related to ownership, access, privacy, security, and community. Information technology affects fundamental rights involving copyright protection, intellectual freedom, accountability and security. According to Tucker [5], in its 1991 Computing Curriculum report, Association of Computing Machinery, in conjunction with the Institute of Electrical and Electronic Engineers, identified the importance of including a "social and professional context" as part of the core curriculum for all computer science majors. This report highlights the need of students to understand the basic cultural, social, legal and ethical issues inherent in the discipline of computing.

The structure of the paper is as follows. This paper begins by presenting the introduction of the paper. It continues with a literature review and followed by methodology and results. The final section concludes the study. 


\section{LITERATURE REVIEW}

Computers have become an integral part of our society. Consequently, both use and abuse of computers have increased dramatically. Although proper use has proven to be beneficial to businesses and professionals, abuse has caused significant losses to businesses society.

\section{What is Computer Ethics}

Ethics is about guiding decision-making between alternatives involving the actions of people, helping to answer questions as to what the individual and society ought to do [6]. In short, ethics is about making judgments about good and evil, or right or wrong.

Computer ethics, sometimes called IT ethics is the ethical concepts that define a moral IT domain or area, are those that define any other domain of human activity. According to Deborah Johnson, computer ethics is the analysis of the nature and social impact of computer technology and the corresponding formulation and justification of policies for the ethical use of such a technology. The number and kinds of application of computing has felt around the world.

The BBC English Dictionary defines ethics as "moral beliefs and rules about right and wrong" [7]. Ethics can also be defined as "the rules of conduct recognized in respect to a particular class of human actions" [8].

\section{Computer Ethics Issues}

The advancement of more complex IT tools and computers is not solely a technological issue. It has effects in a variety of areas ranging from ethical to social, and also legal. Besides the benefits brought by the advancement of the technologies, problems also are arising.

In this respect, the computer or IT use has generated ethical issues that would have been impossible without computer and IT. And also, the lack of noncomputer analogies for moral issues regarding computer supports the uniqueness of computer ethics. There is much debate about IT in relation to social control and privacy, security and reliability, and ethics and professional responsibilities [9].

Computer ethics issues can be classified using the traditional concepts of privacy, property, crime and abuse, power and responsibility, professional practice, accountability, and liability [10]. The major ethical issues that emerge from these various sources include; codes of ethics, intellectual property, data security and accuracy, personal privacy.

\section{Accuracy}

Accuracy represents the legitimacy, precision, and authenticity with which information is rendered. Because of the pervasiveness of information about individuals and organizations contained in information systems, special care must be taken to guard against errors and to correct known mistakes. Difficult questions remain when inaccurate information is shared between computer systems [11]. According to [12], the legal liability issues associated with information. Who is held accountable for the errors? Which party is liable for inexact or incorrect information that leads to devastation of another?

\section{Privacy}

Privacy, a subset of security, is recognized by many ethicists as requiring more attention than previously received in moral theory because of the use of information technology (IT) [13]. Privacy has become an extremely important part of nowadays culture. Privacy is freedom from unsanctioned intrusion (American Heritage Dictionary). It is an implied right based on the Fourth, Fifth, and Ninth Amendments of the Constitution [14].

Privacy may be invaded in four methods. The first is unreasonable intrusion upon a person's seclusion. Appropriation occurs when the use of a person's name or likeness is used for economic benefit. Third is public disclosure of private facts. Finally, false light is publicly characterizing or placing a person in a false light [15]. Most cases concerning invasion of privacy by employers involve intrusion upon seclusion.

\section{Intellectual Property}

Intellectual property refers to creations of the mind: inventions, literary and artistic works, and symbols, names, and images used in commerce. Intellectual property is divided into two categories [16]:

Industrial property includes patents for inventions, trademarks, industrial designs and geographical indications.

Copyright includes literary works such as novels, poems and plays, films, musical works, artistic work 
such as drawings, paintings, photographs and sculptures, and architectural designs. Rights related to copyright include those of performing artists in their performances, producers of phonograms, and those of broadcasters in their radio and television programs.

It is clear that unauthorized downloading and copying software are two major examples of intellectual property issues.

\section{Computer Ethics Scenario}

Scenarios consist of a description of a situation and resulting action. It is widely used by organizations to understand different ways that future events might unfold.

Scenarios related to the field of computing were first illustrated by John Parker, who conducted a workshop attended by a diverse group of professionals, including computer scientists, psychologists, sociologist, and lawyers [14]. Scenarios are commonly used to examine ethical judgments and intentions in many different areas, including information system (IS) [17].

Computer ethics scenario or ethical scenarios or case study is a short narrative of one or more events that involve one or more ethical issue [17]. Basically, with those scenarios, the person involves in the study or evaluation process is expected to analyze the participants' actions and arrive at a judgment concerning their ethical nature.

Ethical issues have been presented by researchers in the past via scenarios or short statements [15]. Sometimes, scenarios in the form of statements were chosen to obtain a larger range of issues. According to [18], the length of the scenarios does not allow for more than a few ethical situations, and the specific content endemic to ethical scenarios limit the generalizations that can be made. Short statements are considered to have less bias than longer statements [18].

Table 1 Scenario Statements

\begin{tabular}{|c|c|}
\hline No. & Scenario Statements \\
\hline 1 & A programmer modifies a bank's \\
\hline (Data & accounting system to hide \\
\hline Accuracy) & $\begin{array}{l}\text { overdrawn account and avoid the } \\
\text { overdraft charge. After making a } \\
\text { deposit, the programmer corrects his } \\
\text { modification. }\end{array}$ \\
\hline
\end{tabular}

Volume XI, No. 1, 2010
2 A person $L$ received software (Intellectual ordered from a mail-order company Property) but also finds another software package sent in error. The extra software was not listed on the invoice. The person $L$ keeps the program and does not pay for it.

3 A person $M$ who was inadvertently (Accessibility) given access free of charge to proprietary program uses it without paying the fee.

4 A company employee contracts with

(Privacy) a government agency to process data involving information about children and their parents. The employee copies the data at the boss's request. The job contract does not prohibit this.

$5 \quad$ Person $R$ likes to play practical (Privacy) jokes on friends. Once he/she tried to $\log$ on to Person $P$ 's account guessing his password was his wife's name. Once he/she had access, he/she installed a program that would flash the message "There is no Escape" every time the escape key was pressed. Person $P$ discovered the joke a few days later and was upset.

6 A person $R$, buy online software in (Intellectual order to his/her project Property) enhancement. Prior to use the software, a friend of person $R$ who is person $Y$, needs to use the software. So person $R$ shares his/her username and password for further development.

7 At work, programmer $K$ does not (Data have to correct inaccurate Accuracy) information he/she may hold about customers.

$8 \quad$ A computer programmer built small (Accessibility) computer applications (programs) to give his friends. He would frequently go to his office on Saturday when no one was working and use his employer's computer to develop applications. He did not hide the fact that he was going into the building; he had sign a register at a security desk each time he entered. 


\section{Accuracy Scenario}

Misinformation has a way of fouling up people's lives, especially when the party with the inaccurate information has an advantage in power and authority. Below is a scenario related to the accuracy issue [19]:

Consider the plight of one Louis Marches. Marches, an immigrant, was a hard working man who, with his wife Eileen, finally saved enough money to purchase a home in Los Angeles during the 1990s. They took out a long term loan from Crocker National Bank. Every month Louis Marches would walk to his neighborhood bank, loan coupon book in hand, to make his payment of $\$ 195.53$. He always checked with care to insured that the teller had stamped "paid" in his book on the proper line just opposite the month for which the payment was due. And he continued to do his long after the bank converted to its automated loan processing system.

One September a few years ago Marches was notified by the bank that he had failed to make his current house payment. Marches grabbed his coupon book, marched to the bank and, in broken English that showed traces of his old country heritage, tried to plain to the teller that this dunning notice was wrong. He had made his payment he claimed. The stamp on his coupon book proved that he had paid. The teller punched Marches' loan number on the keyboard and reviewed the confirm Marches' claim, nor subsequently could the head teller, nor the branch manager. When faced with a computer generated screen that clearly showed that his account was delinquent, this hierarchy of bankers simply ignored the entries recorded in his coupon book and also his attendant raving. Confused, Marches left the bank in disgust.

In October, however, Marches dutifully went to the bank to make his next payment. He was told that he could not make his October payment because he was one month in arrears. He again showed the teller his stamped coupon book. She refused to accept it and he stormed out of the bank. In November he returned on schedule as he had done for over 20 years and tried to make his payment again, only to be told that he was now two months in arrears. And so it went until inevitably the bank foreclosed. Eileen learned of the foreclosure from an overzealous bank debt collector while she was in bed recovering from a heart attack. She collapsed upon hearing the news and suffered a near fatal stroke which paralyzed her right side. Sometime during this melee Marches, who until this time had done his own legal work, was introduced to an attorney who agreed to defend him. They sued the bank. Ultimately, after months of anguish, the Marches received a settlement for $\$ 268,000$. All that the bank official who testified could say was, "Computers make mistakes. Banks make mistakes, too."

\section{Privacy Scenarios}

Examples of the scenarios addressed in this section are related to the privacy issues. They are based on scenario projects identified by the University of Illinios at Springfield DOLCE (Developing Online Computer Ethics) project [18, 20-22].

Loan Zip: You have advocated and started the use of data mining at a major credit card firm where you work. You soon discover a correlation between customer loan defaults and 25 zip codes.

What should you do with this information?

- You should check to see if you can find a correlation between other zip codes and customers who faithfully pay off their loans.

- You should go no further. In fact, you have already gone too far since, through this data mining, you have violated the right to privacy of these individuals.

- You should test these correlations further. Then, if they seem to hold, you should go to your supervisor and recommend not giving loans to people in these zip codes.

E-mail: You are a supervisor. While reviewing the emails of your employees, you discover that one of them is using the system to operate a weekly football betting pool.

What should you do?

- Nothing. You should not have been reviewing emails anyway.

- Fire the employee. He or she is robbing the company of time and money.

- Make it clear to the employee that this is not acceptable. Outline a series of punitive measures that you will take should this activity continue.

Monitor: You are the supervisor of a medium sized business. You suspect that the employees under your management are goofing off, but you have no proof. Software exists that can monitor employees and measure their productivity.

What should you do?

- Purchase the software and comprehensively monitor every action of your employees. 
- $\quad$ Send a memo to your employees threatening to monitor their activities if they don't get more productive.

- Purchase the software but only monitor employees whom you suspect are goofing off.

- Implement other measures, short of computer monitoring, to measure the productivity of your employees.

Uni Use: You are the network administrator for a university. It has been brought to your attention that a student is using the University's Internet access, along with the student's personal computer to post content on a questionable web site she owns, hosted by another Internet Service Provider. All content in question on the student's personal computer is encrypted.

What should you do?

- Confiscate the student's computer and retrieve the encrypted files to verify the accusations.

- Suspend the student for violating the University's terms of service.

- Speak to the student about his activities.

Chip Implant: A computer chip manufacturer from Florida has announced that a microchip that can be implemented under the skin is ready to be marketed. The company spokesman said that it has conducted extensive tests and has concluded that the chip poses absolutely no threat to human health. The chip is easy to implant and easy to remove. The CEO of the Company, Ms. Doe, told reporters that the company is very proud of this breakthrough achievement and its potential contributions in the areas of security and human health to mention a few. You are the CIO of a major airport. The CEO has asked you to look into implementing these chips for all the operating and security personnel. By implanting these chips, the CEO thinks it will greatly enhance the security in airports. He said, "After 9/11 we all could use more security. This chip will make events such as $9 / 11$ extremely difficult if not impossible in the future".

What should you do?

- Prepare a plan to implement the new security chips. The more security the better.

- Tell the CEO that a step such as this should be approached cautiously. Convene a study to look into this more.

- Reject this idea, it is way too invasive.

Spam: You have invented a really good software product but need away to market it. Today, you received an e-mail message offering you a $\mathrm{CD}$ containing 12 million e-mails addresses plus professional e-mailing software. For the reasonable price of $\$ 249$ for the CD and for the e-mailing software, you can mass market this product.

What should you do?

- Order the mass marketing software. Hopefully someone will order your software.

- Hold off on ordering the software. If you cannot get orders any other way, you can use it then.

- Do not ever order the software. Find different ways to market the software.

\section{Intellectual Property Scenarios}

Below are examples of scenarios that are related to the intellectual property issues [20] [21].

- Jason R. designed and posted a Star Wars web site. Once the site started receiving 40,000 hits a day, he received a phone call from Lucas film asking him to shut it down. Jason posted excerpts of the phone conversation on his web site. Lucas film was then flooded with angry e-mail messages from fans who felt the company was exerting totalitarian control over products to which they felt a deep personal connection.

- Ms. Harris received e-mail from someone who liked the gargoyle image on the Uni High Library's web page and wanted to know if he could use it on his school library's web page. The art teacher, who created the image for the school, wrote back to him, explaining that the image belonged to the University and that, furthermore, it had special significance as the image that identifies Uni High. She thanked him for his interest, but told him that she could not grant permission for him to use it.

- Malcolm has a web page on the topic of guitars. He has collected a truly astonishing amount of information and receives many complimentary e-mail messages from sailing enthusiasts. He has downloaded numerous pictures and articles he finds on other web sites, and is always careful to give credit by citing the original sources.

- Larry is a fan of a superheroes cartoon which has an accompanying web site. He particularly likes one of the characters. He copies the character's web page onto his own web page, but changes the name of the character to "Larry". Several weeks later, the school system administrator is contacted 
by the company that produces the show and the web page. They threaten to sue the school of the site is not immediately removed.

- Ken does not have much money to buy new music. Instead, he checks out compact disks (CDs) from the public library and rips them, or copies music files from free sharing sites or friends' computers. When he does have money, he either buys CDs the library does not have or downloads songs from iTunes for $\$ .99$ a piece.

Other examples of property issues in scenarios form is presented in Table 2 .

Table 2. Property Issues in Scenario Statements

\begin{tabular}{cl} 
No. & \multicolumn{1}{c}{ Scenario Statements } \\
\hline 1 & $\begin{array}{l}\text { Use by others of software or other intellectual } \\
\text { property you have created without your } \\
\text { consent. }\end{array}$ \\
2 & $\begin{array}{l}\text { Development of viruses, worms, and Trojan } \\
\text { horses. }\end{array}$ \\
3 & $\begin{array}{l}\text { Hacking without evil intent. } \\
4\end{array}$ \\
5 & $\begin{array}{l}\text { Cracking with evil intent. } \\
\text { Distribution of viruses, worms, and Trojan } \\
\text { horses. } \\
\text { Making copies of someone else's software } \\
\text { for your personal use. }\end{array}$
\end{tabular}

\section{METHODOLOGY}

This part presents and describes the instrument and pilot study conducted for this project.

\section{Instrument}

The instrument of the study, namely, questionnaire was structured based on the goal. The aim of this questionnaire is to analyze students' perception on IT ethical issues in Malaysian higher education environment. The questionnaire was divided into two sections. The first part seeks the profile of respondent, while second part comprises of eight ITrelated scenarios. For each scenario, there are nine measures to which respondents need to give their opinions. The questionnaire was personally administrated. The advantage of personally administrated questionnaire is we are able to collect data within a short time.

The survey conducted based on the six questions in the Table 3 below. Scenarios are commonly used to examine ethical judgments and intentions in many different areas. Consistent with this approach, scenarios developed and were adopted (Table 1).
Measures of moral intensity were adapted from prior research, as were items that measured ethical perceptions and intentions [23].

Table 3. Questions of Moral Intensity.

No. Question

Q1 The overall harm (if any) done as a result of the actor's action would be very small.

Q2 Most people would agree that (the actor's) actions are wrong.

Q3 (The actor's) actions will not cause any harm in the immediate future.

Q4 There is a very small likelihood that (actor's) actions will actually cause any harm.

Q5 If (the actor) is a personal friend of her/his boss, the action is wrong.

Q6 (The actor's) actions will harm very few people (if any).

Moral intensity is multidimensional, consisting of six components: 1) magnitude of consequences - the aggregate harm or benefits of the act; 2) social consensus - the degree to which others think the act is good or evil; 3) temporal immediacy - the length of time between the act and its consequences; 4) probability of effect - the likelihood that the act will cause harm or benefits; 5) proximity - the social distance between the decision maker and those affected by the act; 6 ) concentration of effect - the number of people affected by the act (Table 3)[23].

The questionnaires were distributed to 100 computer science undergraduate students at University Technology Malaysia (UTM) International Campus. It was found no major changes were required on the questionnaire's layout or wordings. A response rate of $100 \%$ recorded. The returned questionnaires were then analyzed using SPSS 16.0.

\section{RESULTS}

This section will present the results of the respondents which are Table 4 and Table 7 represented for intellectual property scenario, Table 4 and Table 9 represented for data accuracy while Table 5 and Table 6 represented for privacy scenario. 
Table 4. Percentage of respondents for Scenario 1.

\begin{tabular}{|c|c|c|c|}
\hline \multicolumn{4}{|c|}{$\begin{array}{l}\text { A programmer modifies a bank's accounting } \\
\text { system to hide overdrawn account and avoid the } \\
\text { overdraft charge. After making a deposit, the } \\
\text { programmer corrects his modification. }\end{array}$} \\
\hline \multirow[b]{2}{*}{ No } & \multicolumn{3}{|c|}{ Responses } \\
\hline & Agree (\%) & $\begin{array}{c}\text { Neutral } \\
(\%)\end{array}$ & $\begin{array}{c}\text { Disagree } \\
(\%)\end{array}$ \\
\hline Q1 & 38.1 & 34 & 27.9 \\
\hline Q2 & 56.6 & 27.3 & 16.1 \\
\hline Q3 & 27.1 & 29.2 & 43.7 \\
\hline Q4 & 35.3 & 40.4 & 24.2 \\
\hline Q5 & 47.5 & 32.3 & 20.3 \\
\hline Q6 & 47.5 & 32.3 & 20.2 \\
\hline
\end{tabular}

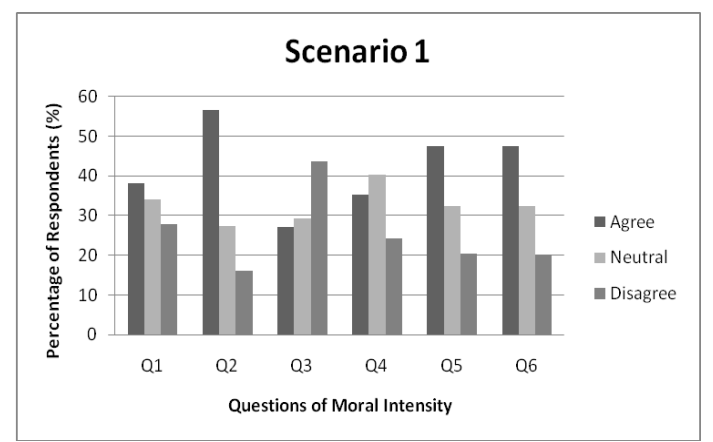

Figure 1. Percentage of respondents for Scenario 1

Based on Table 4 and Figure 1 above, there are responses about the scenario 1; programmer who modifies a bank's account system to hide overdrawn account and avoid the overdraft charge. According to the Q2, more than half respondents indicate $(56.6 \%)$ and other questions also showed the percent of respondents indicates agree higher than disagree, except for Q3; which are strongly feel that ethical conduct is important.

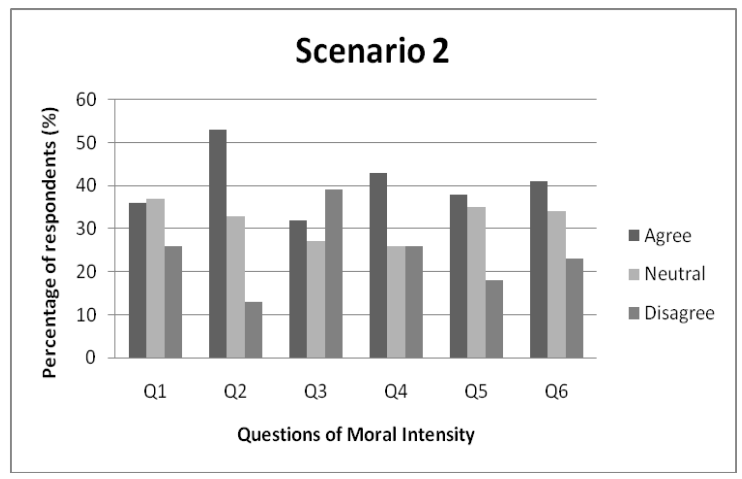

Figure 2. Percentage of respondents for Scenario 2
Table 5. Percentage of respondents for Scenario 2.

Scenario 2: (Intellectual Property)

A person $L$ received software ordered from a mailorder company but also finds another software package sent in error. The extra software was not listed on the invoice. The person $L$ keeps the program and does not pay for it.

\begin{tabular}{cccc}
\hline & \multicolumn{3}{c}{ Responses } \\
\cline { 2 - 4 } No & Agree (\%) & Neutral (\%) & Disagree (\%) \\
\hline Q1 & 36.0 & 37.0 & 26.0 \\
Q2 & 53.0 & 33.0 & 13.0 \\
Q3 & 32.0 & 27.0 & 39.0 \\
Q4 & 43.0 & 26.0 & 26.0 \\
Q5 & 38.0 & 35.0 & 18.0 \\
Q6 & 41.0 & 34.0 & 23.0
\end{tabular}

Based on Table 5 and Figure 2, the respondents' judgment of a person who kept software that was not ordered or paid for, are clearly indicates (53\%) strongly feel that ethical conduct is important. However, only (13\%) are not strongly inclined to be ethical in their opinion while $(33 \%)$ of respondents are neutral.

Table 6. Percentage of respondents for Scenario 4

\section{Scenario 4: (Privacy)}

A company employee contracts with a government agency to process data involving information about children and their parents. The employee copies the data at the boss's request. The job contract does not prohibit this.

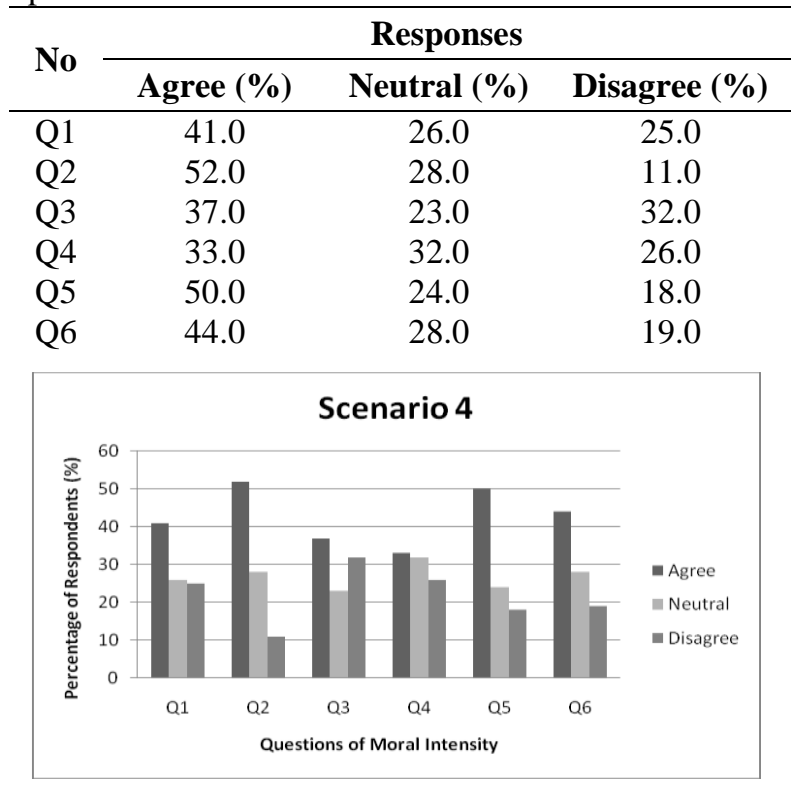

Figure 3. Percentage of respondents for Scenario 4 
In Scenario 4, copying data from a contract job was an unethical action when more than half of respondents indicate $(52 \%)$ agrees that the employee's action is wrong. They argued that any data collected by the government is available for public use, but others expressed concern about infringing on people's privacy. This is shown in Q2 on Table 6 and Figure 3. For some of the respondents, they prefer to be unethical when the statistics showed that $(11 \%)$ of them choosing disagree, while (28\%) are tending to choose neutral.

Table 7. Percentage of respondents for Scenario 5.

Scenario 5: (Privacy)

Person $R$ likes to play practical jokes on friends. Once he/she tried to $\log$ on to Person $P$ 's account guessing his password was his wife's name. Once he/she had access, he/she installed a program that would flash the message "There is no Escape" every time the escape key was pressed. Person $P$ discovered the joke a few days later and was upset.

\begin{tabular}{cccc}
\hline & \multicolumn{3}{c}{ Responses } \\
\cline { 2 - 4 } No & Agree (\%) & Neutral (\%) & $\begin{array}{c}\text { Disagree } \\
(\%)\end{array}$ \\
\hline Q1 & 30.0 & 27.0 & 35.0 \\
Q2 & 54.0 & 12.0 & 34.0 \\
Q3 & 22.0 & 12.0 & 57.0 \\
Q4 & 35.0 & 32.0 & 25.0 \\
Q5 & 35.0 & 36.0 & 21.0 \\
Q6 & 42.0 & 26.0 & 24.0
\end{tabular}

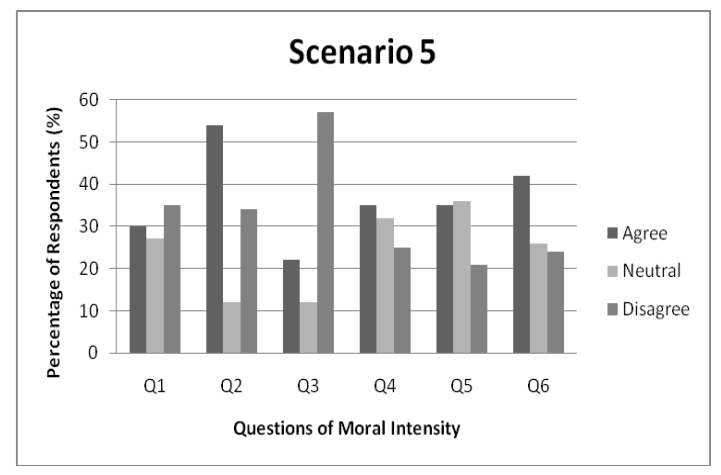

Figure 4. Percentage of respondents for Scenario 5.

According to the Table 7 and Figure 4, Q2, tampering with the computer to create a "No Escape" message when the escape key is pressed are unethical behavior when slightly over than half of respondents $(54 \%)$ prefer to agree with the people's opinion. It is because one's computer viewed as personal and private, and tampering is an invasion of privacy. However, there are (34\%) and (26\%) of respondents are not strongly tending to be ethical and neutral, respectively.

Table 8. Percentage of respondents for Scenario 6.

\section{Scenario 6: (Intellectual Property)}

A person $R$, buy online software in order to his/her project enhancement. Prior to use the software, a friend of person $R$ who is person $Y$, needs to use the software. So person $R$ shares his/her username and password for further development.

\begin{tabular}{cccc}
\hline \multirow{2}{*}{ No } & \multicolumn{3}{c}{ Responses } \\
\cline { 2 - 4 } & Agree (\%) & Neutral (\%) & Disagree (\%) \\
\hline Q1 & 40.0 & 37.0 & 16.0 \\
Q2 & 35.0 & 34.0 & 23.0 \\
Q3 & 25.0 & 37.0 & 30.0 \\
Q4 & 32.0 & 33.0 & 27.0 \\
Q5 & 31.0 & 35.0 & 26.0 \\
Q6 & 26.0 & 30.0 & 36.0
\end{tabular}

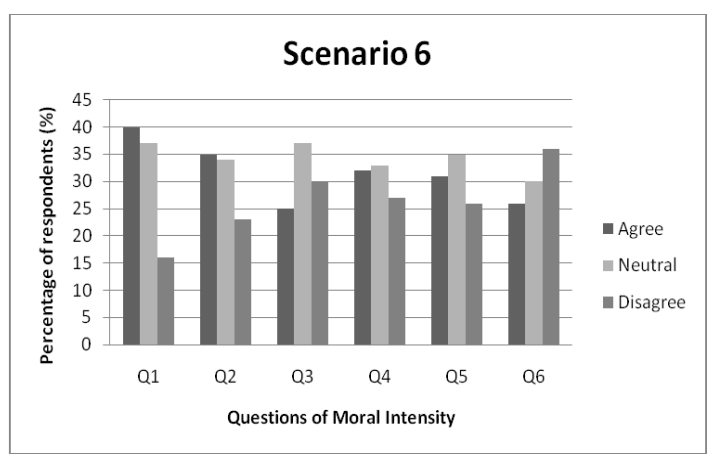

Figure 5. Percentage of respondents for Scenario 6.

Scenario 6 is all about a person $R$ who shares his/her username and password to his/her friend for the further development after that person bought software via online. As depicted in the Table 8 and Figure 5, Q2 above, more than quarter of respondents (35\%) shows the ethical behavior which are disagree that person R's action while (23\%) of the respondents disagreed that the opinion of people (unethical behavior). The rest chooses neutral. 


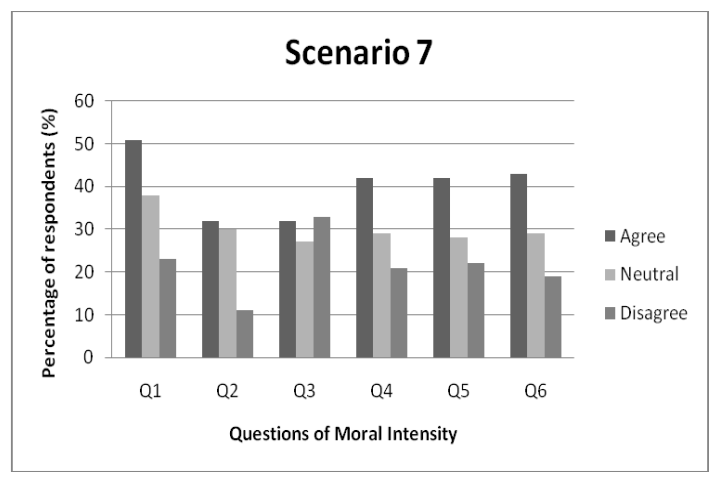

Figure 6. Percentage of respondents for Scenario 7.

Table 9. Percentage of respondents for Scenario 7.

\begin{tabular}{|c|c|c|c|}
\hline \multicolumn{4}{|c|}{$\begin{array}{l}\text { Scenario 7: (Data Accuracy) } \\
\text { At work, programmer } K \text { does not have to correct } \\
\text { inaccurate information he/she may hold about } \\
\text { customers. }\end{array}$} \\
\hline \multirow{2}{*}{ No } & \multicolumn{3}{|c|}{ Responses } \\
\hline & Agree (\%) & Neutral (\%) & Disagree (\%) \\
\hline $\mathrm{Q} 1$ & 51.0 & 38.0 & 23.0 \\
\hline Q2 & 32.0 & 30.0 & 11.0 \\
\hline Q3 & 32.0 & 27.0 & 33.0 \\
\hline Q4 & 42.0 & 29.0 & 21.0 \\
\hline Q5 & 42.0 & 28.0 & 22.0 \\
\hline Q6 & 43.0 & 29.0 & 19.0 \\
\hline
\end{tabular}

According to Scenario 7 from the Table 9 and Figure 6 , the respondents agree to all the questions given except Q3 which is the respondents disagree are more (1\%) than percent of agree. Q1 showed highest percent; more than half respondents indicate $(51.0 \%)$ to agree. This showed that most of the respondents strongly inclined to be ethical in this scenario.

\section{CONCLUSION}

Computer ethics issues such as data accuracy, privacy and intellectual property should receive more attention in the ICT field. The pervasive nature of ICT has conceivably made more people, society, and organizations aware of the relevant ICT issues. In this study, the results indicate that there are more than half of respondents are aware about the misuse and abuse of computer pertaining to all six scenarios regarding accuracy, privacy and intellectual property. In fact, they also do not even know about computer ethics by looking at the analysis of respondents who are chosen neutral responses which are contributed higher percentage than unethical behavior. In this respect, Ellis and Griffith stated that the significance of understanding ICT ethical issues is due to their potential in the business arena for significant security and productivity losses. Thus, in order to improve computer ethics or ICT ethics, an overlooked and potentially effective deterrent is the identification of unique and situational characteristics of IS or IT personnel who act ethically or unethically [11]. This identification then could lead to the formulation of more effective ways of solving the problem of unethical use of ICT. In future, thorough efforts should be undertaken to specify how best to address the ethical issues and its' drawback that will occur in the organizational environment.

\section{REFERENCES}

1. Leonard, L.N.K., \& Cronan, T.P. (2005). Attitude Toward Ethical Behavior in Computer Use: A Shifting Model. Industrial Management \& Data Systems, Emerald group Publishing Limited, 105(9), 1150-1171.

2. Maner, W. (1980). Starter Kit in Computer Ethics. Hyde Park, New York: Helvetia Press and the National Information and Resource Center for Teaching Philosophy.

3. Walter, W.(1996). Unique Ethical Problems in Information Technology. In Terrell Ward Bynum and Simon Rogerson (Ed.), Global Information Ethics, 137-152. Opragen Publications. (the April 1996 issue of Science and Engineering Ethics).

4. Floridi, L. (1999), 'Information Ethics: On the Theoretical Foundations of Computer Ethics', Ethics and Information Technology 1(1), pp. 3756. Preprint from http://www.wolfson. ox.ac.uk/ floridi/papers.htm.

5. Tucker, A. (1991). (Ed.) Computing Curricula 1991: Report of the ACM/IEEE-CS Joint Curriculum Task Force, New York: ACM Press.

6. Floridi, L. (2006). What Is Information Ethics?. Microsoft Research Summer School 2006.

7. BBC English Dictionary. (1992). Harper Collins, London.

8. Wong, E.Y.W. (1995). How Should We Teach Computer Ethics? A Short Study Done in Hong Kong. Computer Education, 25, 179-191,4 Dec.

9. Heron, W.T., Cavico, F., Mujtaba, B.G., \& Pellet, P.F. (2007). Ethics and Information Technology Professionals: An Examination of Gender, Age, Career Stage, Education Level and Ethics Training Variables. Proceedings of 2007 EABR (Business) \& ETLC (Teaching) Conference, Venice: Italy, 1-13.

10. Myers, M.D. (1996). Ethical Dilemmas in the Use of Information Technology: An Aristotelian Perspective. Ethics and Behavior, 6(2), 153-160.

11. Ellis, T., \& Griffith, D. (2001) The Evaluation of IT Ethical Scenarios Using a Multidimensional Scale. The DATA BASE for Advances in Information Systems, 32(1), 75-85.

12. Straub, D.W., \& Nance, W.D. (1990). Discovering and Disciplining Computer Abuse in Organization: A Field Study. MIS Quarterly, 14(1), 45-60. 
13. Parker, B.D. (1979). Ethical Conflicts in Computer Science and Technology. Arlington, Virginia: AFIPS Press.

14. R. August, R., Ferrera, G., Linchtenstein, S., Reder M., \& Schiano, W. (2001). Cyberlaw, West Thomson Learning: USA.

15. Brey, P. (2000) Disclosive Computer Ethics. Computers and Society, 30(4), 10-16.

16. Chieh, C., \& Kleiner, B. (2003). How Organizations Manage the Issue of Employee Privacy Today. Management Research News, 26, 82-88.

17. WIPO. (2008). World Intellectual Property Organization. Switzerland, Available: http://www.wipo.int/freepublication/en/intproper ty/450/wipo_pub_450.pdf

18. Alpert, S. (2005). Privacy Case Study Question. University of Illinois at Springfield DOLCE Project.

19. Mason, R. O. (1986). Four Ethical Issues of the Information Age. MIS Quarterly, 10(1), 5-12.

20. Frank, M. (2005). Marketing Email. University of Illinois at Springfield DOLCE Project.

21. Mahadev. (2005) Innovative New Micro Chip Ready for Marketing. University of Illinois at Springfield DOLCE Project.

22. Frey. (2005). Grey matters in computer ethics. University of Illinois at Springfield DOLCE Project.

23. Singhapakdi, A., Vitell, S.J., \& Kraft, K.L. (1996). Moral Intensity and Ethical DecisionMaking of Marketing Professionals. Journal of Business Research, 36, 245-255.

\section{APPENDIX}

An example of one of real ICT ethical scenarios in Malaysia context.

(Source: New Straits Times, November 11, 2009)

\section{BLOGGER SHOULD STOP SPREADING LIES}

KUALA LUMPUR: Bloggers have been urged to stop spreading lies in their writings, particularly on social and political issues, as they can create controversy and damage the reputation of the government. Broadcasting directorgeneral Datuk Ibrahim Yahya, himself a blogger, said bloggers should act as middlemen when presenting issues to society. "Some bloggers write nonsensical things which are far from the truth and created issues which are not true. "It is difficult to gauge the extent of the truth in blog writings as the writers always hide behind pen names," he said at a dialogue session titled "Blog: Lies or Reality" here today. Ibrahim said although bloggers had the freedom to write, they should always strive for a positive outcome and consider racial sensitivities. Meanwhile, blogger Syed Imran Alsagoff who goes by the moniker "Kuda Ranggi" said like print and electronic media journalists, bloggers should also be exposed to journalism ethics and laws like the Internal Security Act (ISA) and the Offical Secrets Act (OSA). "Bloggers who do not have deep understanding of the provisions of the acts and journalism ethics may resort to writing lies," he said. Syed Imran, a former editor of Bernama said often, blogs on political issues were inclined to lying, incite and degrade the dignity of others. 